\title{
Evaluation of the "Tractor-plow" system using statistical model
}

\author{
Viktor B. Rykov ${ }^{1}$, Sergey I. Kambulov ${ }^{1, *}$, Evgeny I. Trubilin², and Yuri K. Kastidi ${ }^{2}$ \\ ${ }^{1}$ Federal State Budget Scientific Institution «Agricultural Scientific Center" Donskoy unit» «North \\ Caucasian Research Institute of Mechanization and Electrification of Agriculture», Zernograd, Russia \\ ${ }^{2}$ Federal State Budgetary Educational Institution of Higher Education «Kuban State Agrarian \\ University named after I.T. Trubilin» Krasnodar, Russia
}

\begin{abstract}
The article shows one of the ways to evaluate the "machinetractor unit" system using a statistical model from the point of view of reducing non-productive rolling losses. The necessity of making structural changes in order to reduce the filtering capacity of the MTU system for high-frequency perturbations is justified.
\end{abstract}

Previously conducted researches [1] showed that the losses on rolling of the power tool as part of a machine-tractor unit (MTU) make up the main part of all losses on rolling the MTU and largely depend on the frequency composition of the traction force on the hook of the power tool (Pkr). The analysis of the frequency composition of torque (Mti) on the halfaxes of the traction class 8 power equipment with arable, cultivator and seeder units shows that the maxima of the spectral density of Mki are in the low-frequency zone $\left(0-5 c^{-1}\right)$.

However, it is known that the shifting of the energy spectrum of traction (Ркр), as well as the spectra of torque (Мкi) in the area of frequency $\left(10-12 \mathrm{c}^{-1}\right)$ allows to improve traction and dynamic performance of the power unit and quality characteristics of the performed technological processes, including for plowing. In this regard, there is a need to assess the filtering capacity of the MTU system based on the frequency of Ркр and Мкі and to find the transfer function of this system to determine the involuntary rolling losses.

The tasks can be solved using the MTU statistical model constructed by the identification method. This method is based on information about the input and output parameters of systems in their normal operation.

It should be noted that the MTU model is multidimensional, i.e. it includes several input and control actions and has several outputs. Therefore, you should choose the most representative input and output parameters that allow you to identify accurately the internal structure of the model.

In connection with the task of studying unproductive rolling losses of the MTU as an input parameter, it is advisable to take the tractive resistance of an aggregated agricultural machine or a tool (Ркр), and as output parameters - torques on the half-axes of the energy unit (Мкі).

The tractive resistance (Ркр) of an aggregated agricultural machine is the main indicator of its energy intensity.

\footnotetext{
*Corresponding author: kambulov.s@mail.ru
} 
Torques $\left(\mathrm{Mk}_{1}\right)$ on the half-axes describe the energy capabilities of the energy resources used.

The accepted model scheme has the following form:

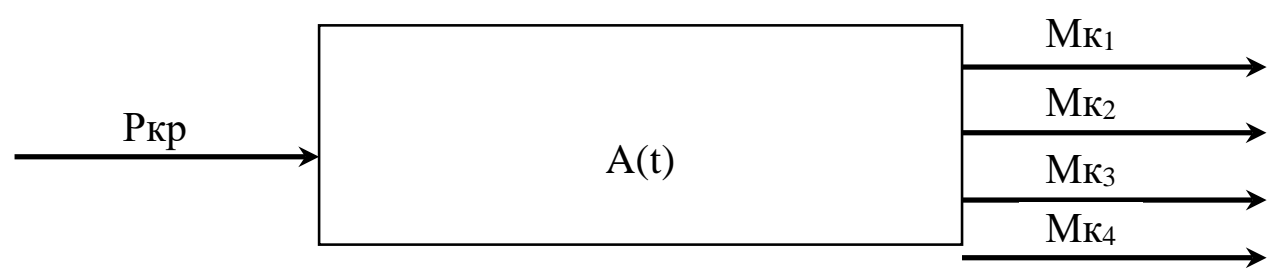

Such a model scheme can be decomposed into a number of dimensional models:

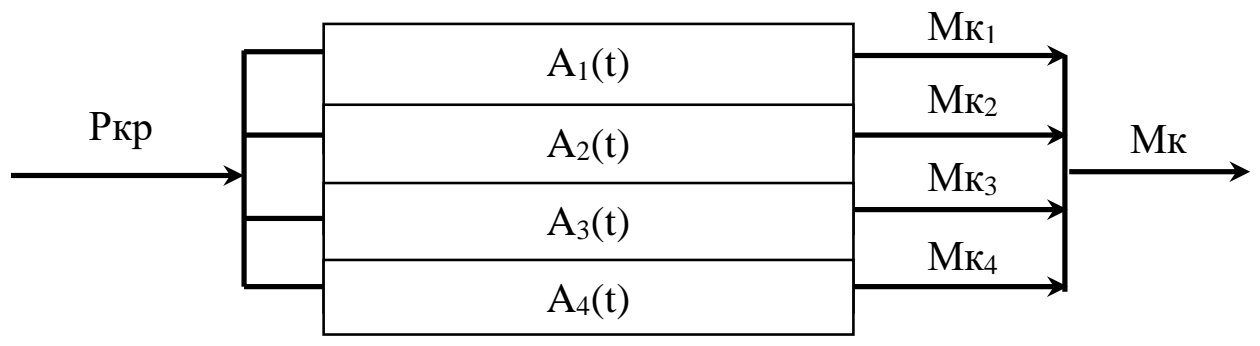

where Ркр - tractive force on the hook of the energy units;

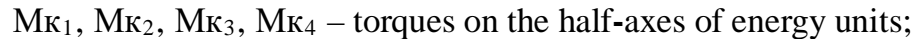

Мк - torque on the output shaft of the engine of the power supply;

$A_{1}(t), A_{2}(t), A_{3}(t), A_{4}(t)$ - model operators.

In this case, the model operator $A(t)$ can be represented as the sum of the operators $\Sigma \operatorname{Ai}(\mathrm{t})[2]$

It is known that in the practical implementation of the identification method, transfer functions, pulse and frequency characteristics of random processes at the input and output of MTU functioning models are taken as operators of agricultural aggregates [2, 3].

On the basis of experimental data [4] using known correlations [5], the identification of an arable MTU as a part of a wheeled traction power vehicle of traction class 8 and a 12body plow were performed when plowing to a depth of 20-22 cm according to the accepted model structure.

Figure 1 shows a fragment of obtained implementations of the tractive effort of the Ркр and torques on the half-axes of the energy units $\left(\mathrm{M}_{\mathrm{K} 1}, \mathrm{M}_{\mathrm{K} 2}, \mathrm{M}_{\mathrm{k} 3}, \mathrm{M}_{\mathrm{K} 4}\right)$ when performing the technological assessment-plowing to a depth of $20-22 \mathrm{~cm}$. 


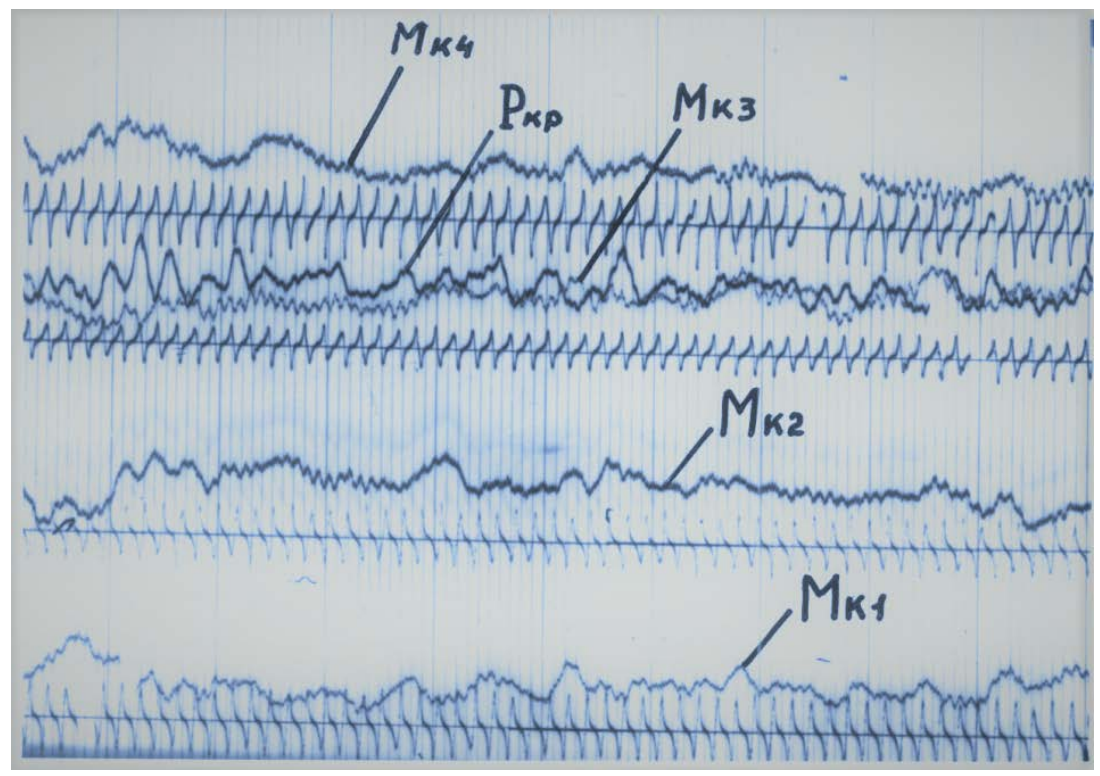

Fig. 1. Fragment of obtained implementations of the Ркр tractive effort and torques moments on the half-axes of the energy units $\left(M_{K} 1, M_{K 2}, M_{k 3}, M_{K 4}\right)$

Statistical and dynamic characteristics of the system were calculated using standard programs for personal computers [6].

Figure 2 shows the normalized correlation functions and standard drag densities when plowing to a depth of $20-22 \mathrm{~cm}$ at different values of the operating mass of the energy units of the traction class 8 .

It can be seen from figure 2 that an increase in the speed of the MTU movement contributes to a certain shift of the maximum energy spectrum of the traction resistance of the unit to the zone of higher frequencies [7]. The maximum of energy spectra for the compared levels of energy saturation of the energy units used corresponds to the frequencies of $0.66-1.66 \mathrm{c}^{-1}$.

When plowing to the same depth with an increase in speed at the same level of energy saturation of the energy units (Figure $2 \mathrm{~b}$ ), there is also a slight shift in the maximum of the energy spectrum towards higher frequencies [8]. However, it should be noted that for all the considered options, the maximum energy spectra of the plow's traction resistance still fall on the low-frequency zone corresponding to the range $0-5 \mathrm{c}^{-1}$. 


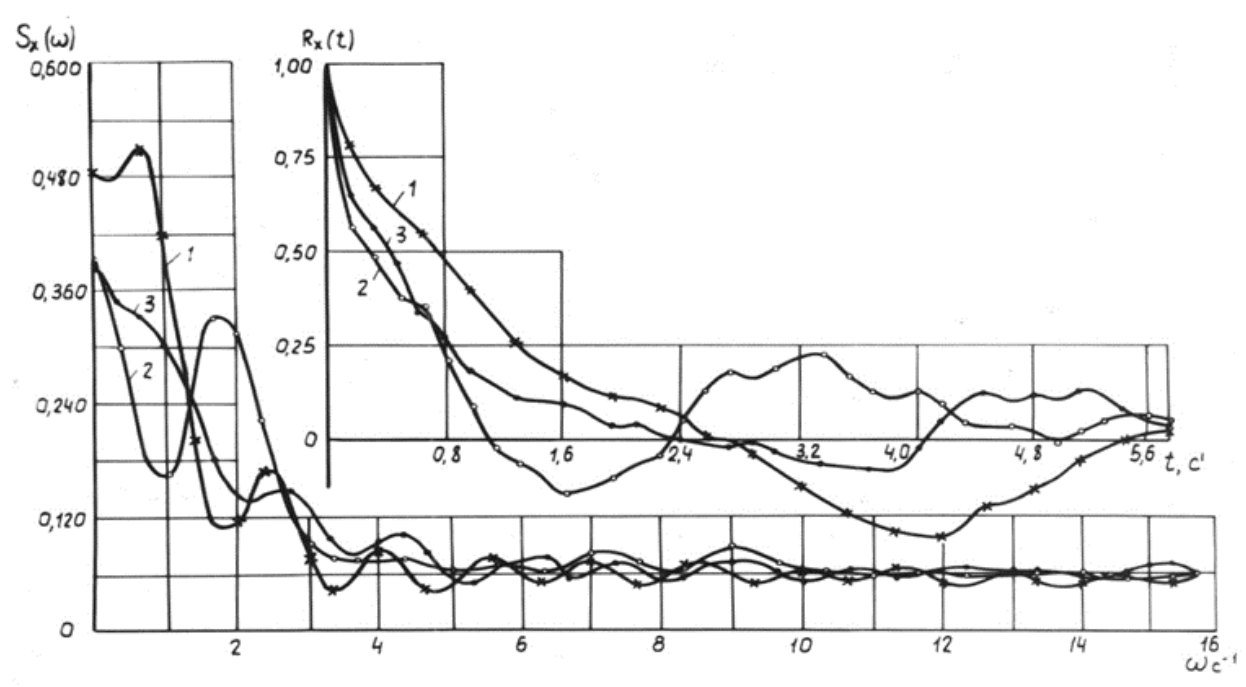

a)

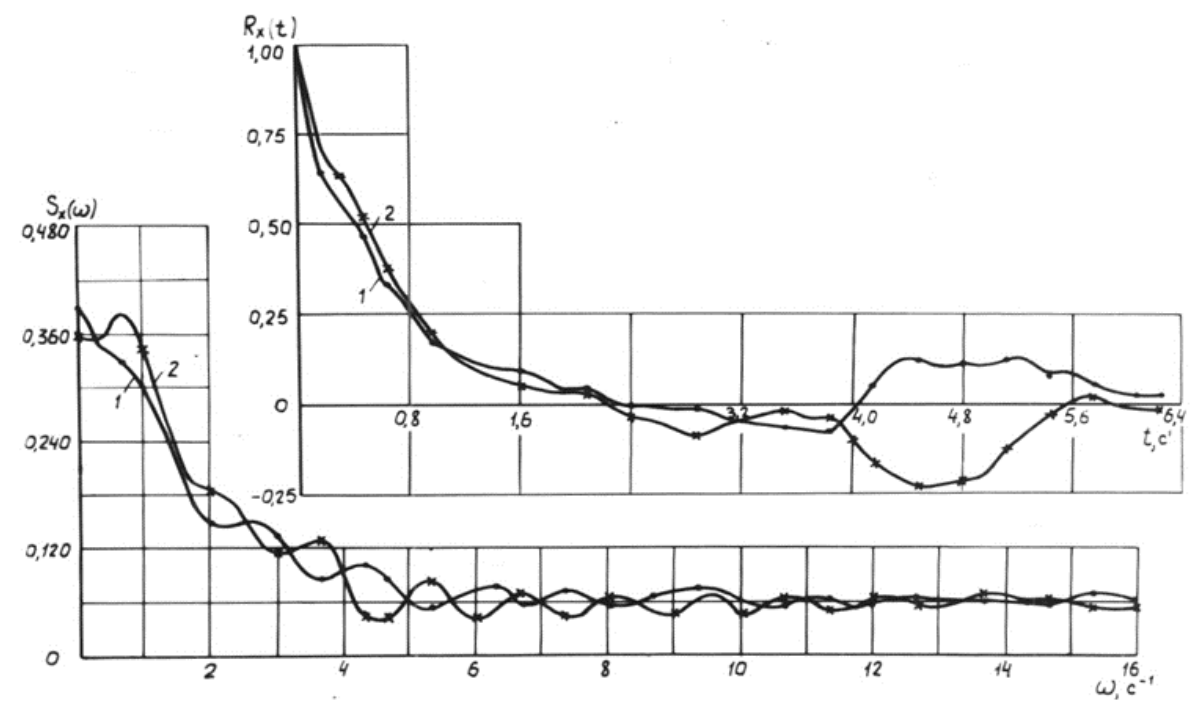

b)

Fig. 2. Normalized correlation functions and standard drag densities of the arable unit (power equipment of the traction class 8,12 -body) plowing depth $20-22 \mathrm{~cm}$

a) at the operating mass of the power equipment $17500 \mathrm{~kg}(1) ; 19000 \mathrm{~kg}$ (2); $22400 \mathrm{~kg}$ (3); ( $\mathrm{V}_{1}=1,8$ $\mathrm{m} / \mathrm{s} ; \mathrm{V}_{2}=2,49 \mathrm{~m} / \mathrm{s} ; \mathrm{V}_{3}=2,80 \mathrm{~m} / \mathrm{s}$ )

b) at the operating mass $22400 \mathrm{~kg}\left(\mathrm{~V}_{1}=1,8 \mathrm{~m} / \mathrm{s} ; \mathrm{V}_{2}=2,80 \mathrm{~m} / \mathrm{s}\right)$

A convenient method of estimating the degree of identity of models of agricultural aggregates is using the coherence function, which determines the degree of linear relationship between variables at the input and output of the model in the frequency domain. In this case, the optimal operator for the criterion of the minimum of the average error is the amplitude-frequency characteristic of the model $A(\omega)$ [3] 


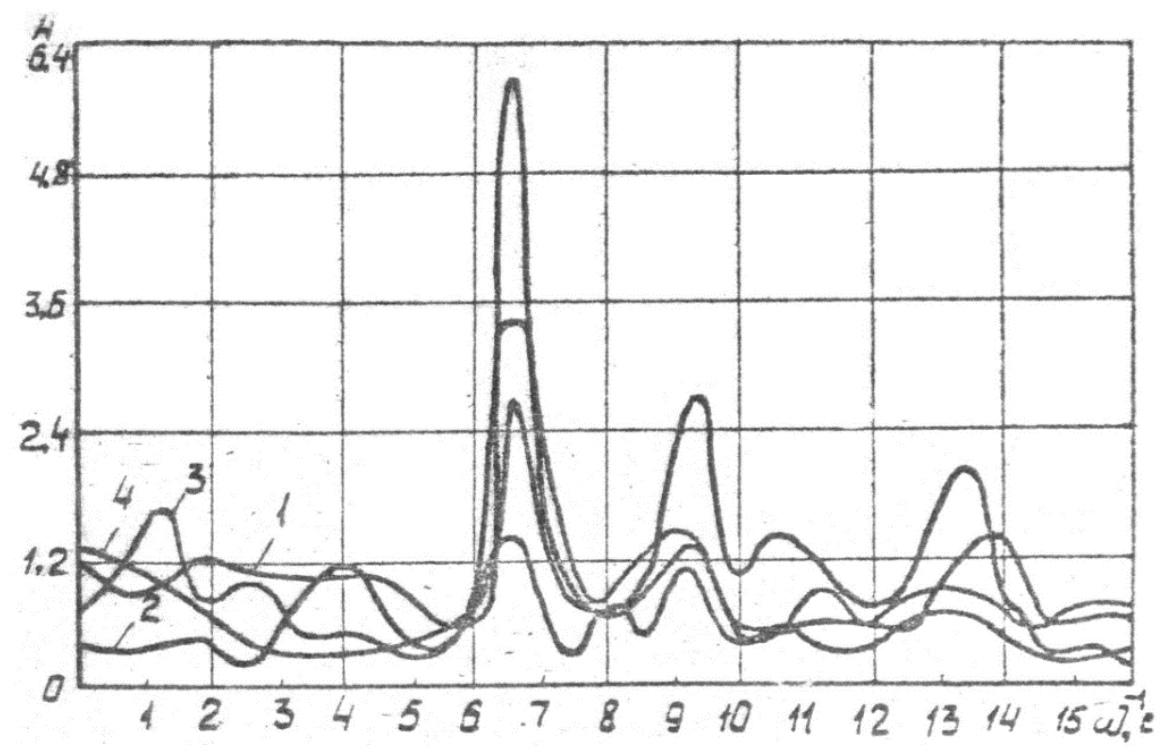

Fig. 3. Amplitude-frequency characteristics of the arable MTU model on channels 1, 2, 3, 4 .

Figure 3 shows the amplitude-frequency features A $(\omega)$ for channels 1, 2, 3, 4 (1; 2 torques on the axles of the front axles; $3 ; 4$ - torques on the axles of the rear axles).

Maximums for all channels are obtained at the same frequency equal to $6.7 \mathrm{c}^{-1}$. The frequency bandwidth is approximately the same for all channels of the model, so the cutoff frequency can be considered equal to $10-11 \mathrm{c}^{-1}$. A sufficiently intense attenuation of the amplitude-frequency characteristics indicates that the system significantly filters the input high-frequency effects.

However, this circumstance does not contribute to reducing the loss of rolling MTU, which is confirmed by the results of our researches [9].

Representing each channel of the model as a second-order aperiodic link, we can define the transfer function of each channel using the expression [3]

$$
W(S)=\frac{k}{T_{2}^{2} \cdot S^{2}+T_{1} \cdot S+1}
$$

Having determined the numerical values of the coefficients by the method of sequential approximation, the transfer ratios of the function over channels will take the form:

$$
\begin{gathered}
W(S)_{1}=\frac{0,94}{0,00001 \cdot S^{2}+0,147 \cdot S+1} \\
W(S)_{2}=\frac{3,91}{0,029 \cdot S^{2}+0,252 \cdot S+1} \\
W(S)_{3}=\frac{1,53}{0,005 \cdot S^{2}+0,049 \cdot S+1} \\
W(S)_{4}=\frac{3,40}{0,078 \cdot S^{2}+1,360 \cdot S+1}
\end{gathered}
$$

Transfer function of the entire system

$$
\mathrm{W}(\mathrm{S})=\mathrm{W}\left(\mathrm{S}_{1}\right)+\mathrm{W}\left(\mathrm{S}_{2}\right)+\mathrm{W}\left(\mathrm{S}_{3}\right)+\mathrm{W}\left(\mathrm{S}_{4}\right)
$$


Figure 4 shows the graphs of the coherence function for each of the channels of the model under consideration.

$$
K^{2}(\omega)=\frac{\left|S_{\text {РкрМк }}(\omega)\right|^{2}}{S_{P \kappa \mathrm{p}}(\omega) * S_{M \kappa i}(\omega)^{\prime}},
$$

where $\left|S_{Р \text { крмк }}(\omega)\right|^{2}$ - the module of mutual spectral density of processes at the input and output of each channel of the model;

$S_{M \kappa i}(\omega)$ - spectral density of the output process by channels;

$S_{P \text { кр }}(\omega)$ - spectral density of the input process.

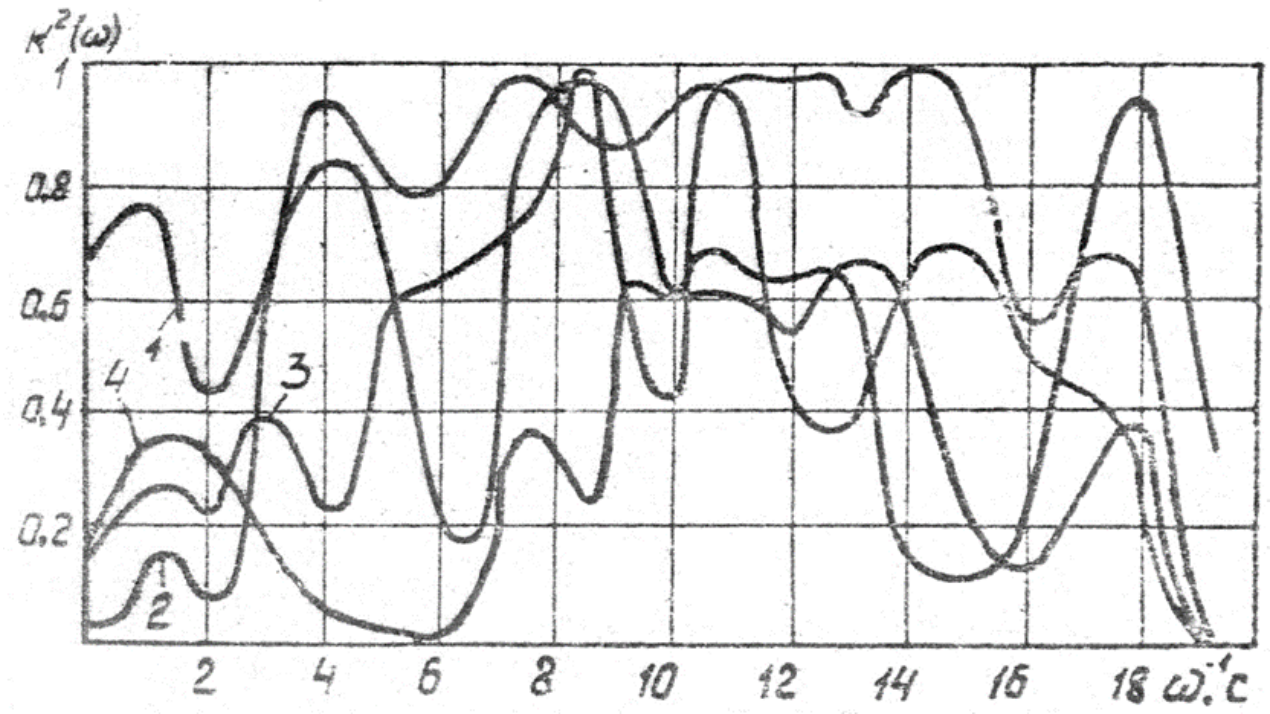

Fig. 4. Coherence function of the components of the arable land model MTU on channels 1, 2, 3, 4

The analysis of graphs (Figure 4) shows that the greatest correlation between the input and output signal for the considered arable unit is observed: on the first channel at frequencies 5-9 $c^{-1}$, on the second channel at frequencies $4-11 c^{-1}$, on the third channel - at frequencies $9-13 c^{-1}$ and $18 c^{-1}$, on the fourth channel - at frequencies $8 c^{-1}$ and $11-15 c^{-1}$.

From the presented data, it can be seen that the largest correlation between input and output signals is observed in a lower frequency zone for the front power bridge (model channels 1 and 2) than for the rear driving bridge (model channels 3 and 4), which is obviously due to different operating conditions of the wheels of the front and rear driving bridges.

\section{Conclusions}

1. The obtained statistical model allows us to evaluate possible design changes in the power transmission of the power unit aimed at reducing unproductive losses, rolling.

2. It is necessary to reduce the filtering capacity of the system for high-frequency disturbances in order to reduce the rolling losses of the arable unit based on a wheeled power vehicle of traction class 8 .

3. It is necessary to develop coupling devices that allow shifting the energy spectrum of the tractive effort of the Ркр in the frequency range of $12-15 \mathrm{c}^{-1}$. 


\section{References}

1.Rykov V.B. The dependence of the resistance force to the rolling of the tractor on the size and nature of the traction force. - In the collection: Improvement of means of mechanization of cultivation of field crops. - Zernograd: VNIPTIMESKH, 1988.

2.Lurye A.B. Statistic dynamics of agricultural units. - M.: Kolos, 1981. - 382 p.

3. Lurye A.B. Wide-cut tillage machines / A.B. Lurye, A.I. Lyubimov. - L.: Machine engineering, 1981. - P. 80-129.

4.Bendat J. Measurement and analysis of random processes / J. Bendat, A. Pirsol. - M.: Mir, 1974. -408 p.

5. Bendat J. Application of correlation and spectral analysis / J. Bendat, A. Pirsol. - M.: Mir, 1983. - $312 \mathrm{p}$.

6. Bendat J. Applied analysis of random data / J.Bendat, A. Pirsol. - M.: Mir, 1989. - 540 p.

7. Modern methods of indentification of systems: Translation from English/ under edition of P.Eykhoff. - M.: Mir, 1983. - 400 p.

8. Rykov S.P. Methods of modeling and assessment of absorbing and smoothing ability of pneumatic tyres in calculations of suspension and fluctuations of wheeled machines. Eng.doctoral thesis, M.: 2005.

9. Volegov A.S. Dynamic features of combined soil-processing sowing units at vegetable seed growing, FSBEI HPE Perm SAA, Perm Agrarian Bulletin, 2013. 